\title{
Milo : l'acropole (la colline du Prophète Élie) - 2018
}

\section{Alain Badie et Jean-Charles Moretti}

\section{OpenEdition \\ Journals}

Édition électronique

URL : http://journals.openedition.org/baefe/1962

DOI : $10.4000 /$ baefe. 1962

ISSN : 2732-687X

Éditeur

ResEFE

\section{Référence électronique}

Alain Badie, Jean-Charles Moretti, « Milo : I'acropole (la colline du Prophète Élie) - 2018 » [notice archéologique], Bulletin archéologique des Écoles françaises à l'étranger [En ligne], Grèce, mis en ligne le 23 décembre 2020, consulté le 22 mars 2021. URL : http://journals.openedition.org/baefe/1962 ; DOI : https://doi.org/10.4000/baefe.1962

Ce document a été généré automatiquement le 22 mars 2021

\section{cc)}

Le Bulletin archéologique des Écoles françaises à l'étranger est mise à disposition selon les termes de la Licence Creative Commons Attribution - Pas d'Utilisation Commerciale - Pas de Modification 4.0 International. 


\title{
Milo : l'acropole (la colline du Prophète Élie) - 2018
}

\author{
Alain Badie et Jean-Charles Moretti
}

\section{NOTE DE L'AUTEUR}

Autorité nationale présente : Éphorie des Cyclades

Numéro de mission : 134

Établissements porteurs de l'opération : EFA

1 À l'invitation de P. Pantou et avec le soutien de l'éphorie des Cyclades, de l'École française d'Athènes et de l'Institut de recherche sur l'architecture antique nous avons poursuivi du 19 au 28 septembre 2018 l'étude engagée en 2016 des vestiges antiques situés dans la cité de Milo sur la colline du Prophète Elie. Le travail a principalement consisté à faire des vérifications pour les mises au propre des relevés (fig. 1) et à progresser dans la rédaction de deux articles, l'un destiné aux actes du colloque sur les Cyclades qui s'est tenu au mois de novembre 2017 au Musée byzantin d'Athènes et l'autre au $B C H$. 
Fig. 1. La plaque de caissons 10 : relevé au 1/10 reproduit au 1/20.

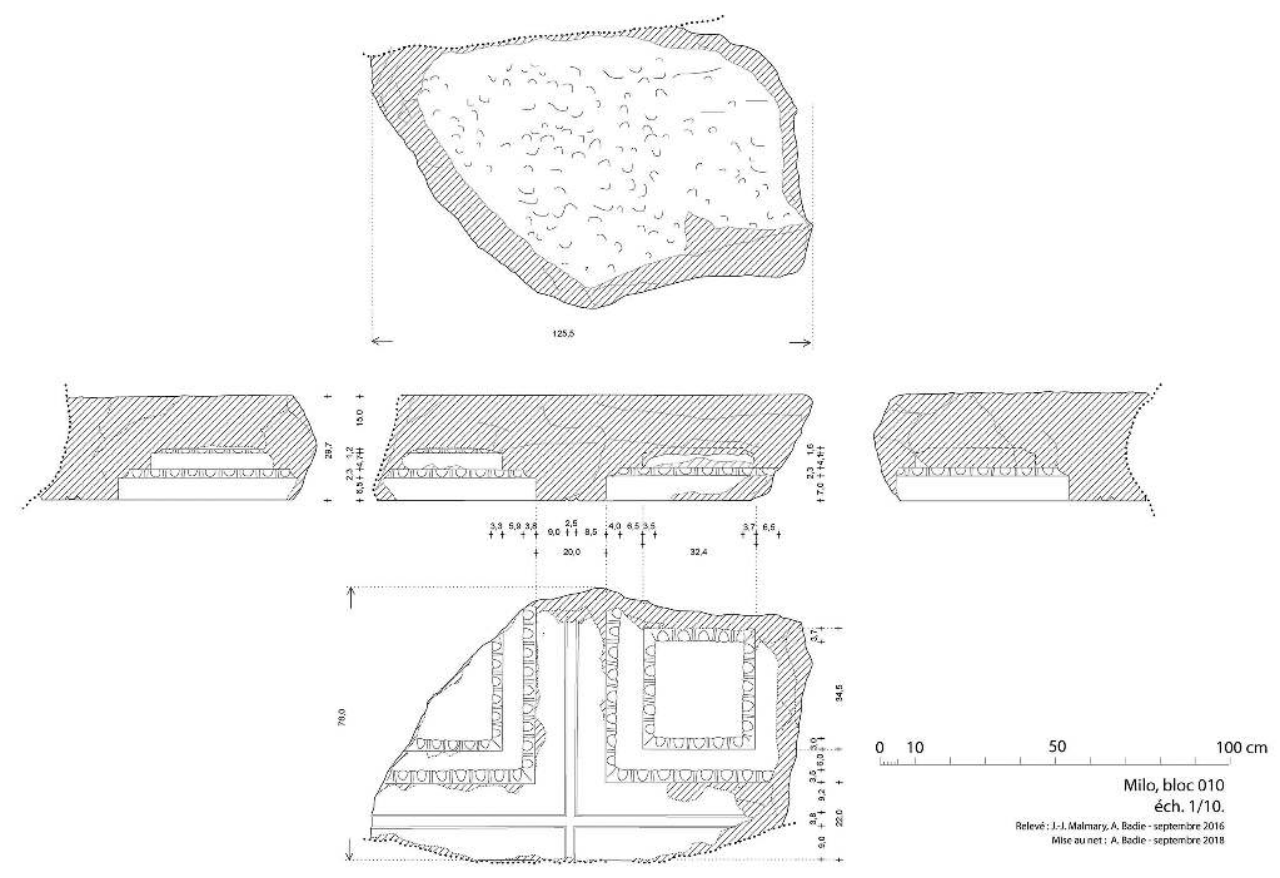

J.-J. Malmary, A. Badie.

2 Un travail spécifique a été entrepris sur les archives de C. Haller von Hallerstein conservées à la Bibliothèque nationale et universitaire de Strasbourg. Haller fit des séjours à Milo en 1816 et 1817, années durant lesquelles il fouilla le théâtre (fig. 2). En 1817, il le fit avec des ouvriers venus d'Athènes qu'il fit loger dans le monastère de Saint Élie. Il y a dessiné, remployés ou erratiques, plusieurs blocs: une plaque de caissons ( $\mathrm{n}^{\circ} 10$ dans notre inventaire), un fût de granit (9), une corniche à denticules et modillons (14) et une frise en doucine (7) que nous y avons retrouvés, mais aussi d'autres blocs qui n'y sont plus : un fût de colonne de marbre blanc, un petit piédestal, un caisson avec une rosette et un chapiteau avec une unique couronne de feuilles dressées. Pour le bloc le plus souvent mentionné par les voyageurs, un fragment de fronton portant une dédicace sur sa corniche horizontale (IG XII 3, 1100), il a recopié le dessin de Fauvel actuellement conservé à la Paris (BnF, Gb 15b Pet Fol, f. 90, n 185 r), sans doute parce que le bloc, actuellement perdu, avait alors déjà été emporté. Les carnets de Haller constituent le dossier d'archive le plus riche actuellement disponible sur la colline du prophète Élie. Leur prise en compte nous a permis de préciser notre connaissance de l'occupation du site à l'époque antique et de son évolution à l'époque moderne. Les dessins qu'ils contiennent assurent, plus que les descriptions des voyageurs, la présence ancienne sur le site de plusieurs des éléments architecturaux que nous y avons trouvés et étudiés. Ils apportent un nouvel argument en faveur de l'hypothèse selon laquelle ces blocs proviennent des monuments érigés dans l'antiquité sur la colline. 
Fig. 2. C. Haller von Hallerstein, croquis avec représentation de la plaque de caissons 10.

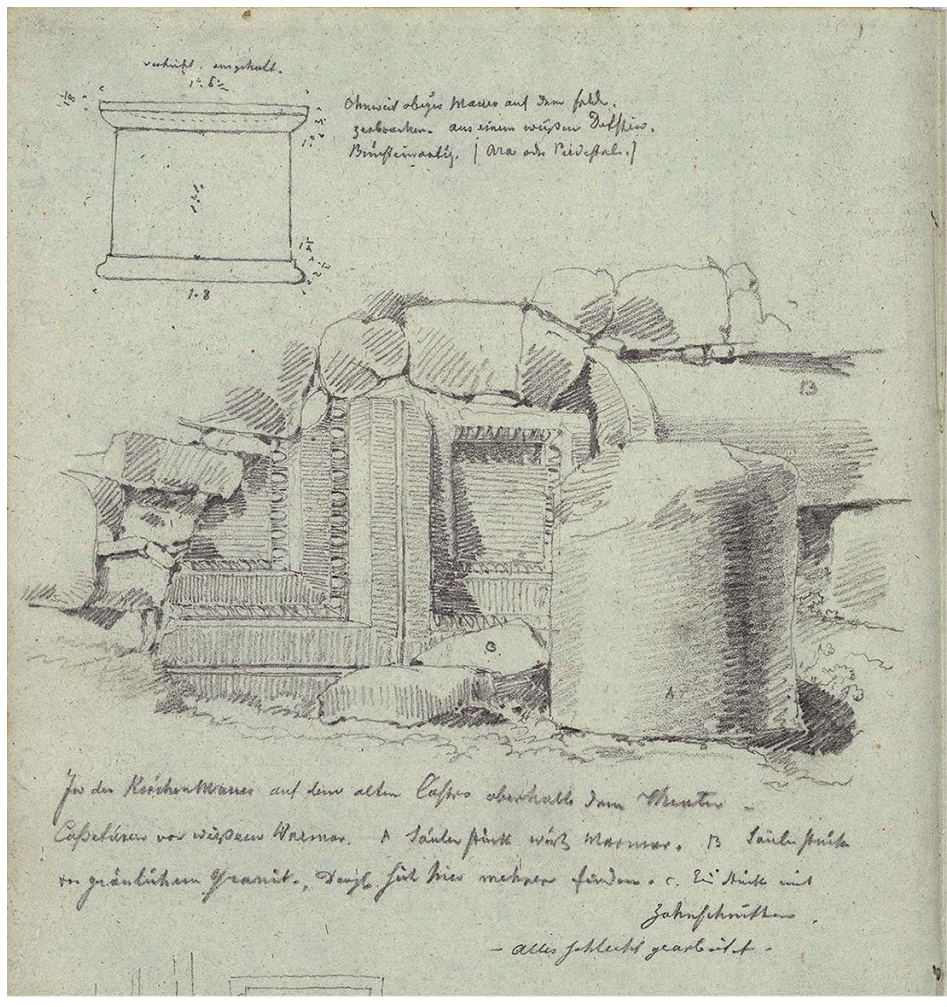

BNU de Strasbourg, MS.2.724,2,25, Chemise intitulée « Milo » contenant des notes et des dessins au crayon effectués à Milos et Siphanto de septembre 1816 à juin 1817, feuillet 439, page de gauche.

\section{INDEX}

\section{Thèmes : EFA}

lieux https://ark.frantiq.fr/ark:/26678/pcrtunPtouUWp9

sujets https://ark.frantiq.fr/ark:/26678/pcrts8SiTTY3Ka, https://ark.frantiq.fr/ark:/26678/

pcrtXk6sdvTjnE, https://ark.frantiq.fr/ark:/26678/pcrtxzTYzVBKas, https://ark.frantiq.fr/ark:/ 26678/pcrtSkipOsBGML

chronologie https://ark.frantiq.fr/ark:/26678/pcrtNzYn31IIAZ

Année de l'opération : 2018

\section{AUTEURS}

\section{ALAIN BADIE}

IRAA, CNRS, AMU, LL2, Lyon, UPPA

JEAN-CHARLES MORETTI

IRAA, CNRS, AMU, LL2, Lyon, UPPA 